
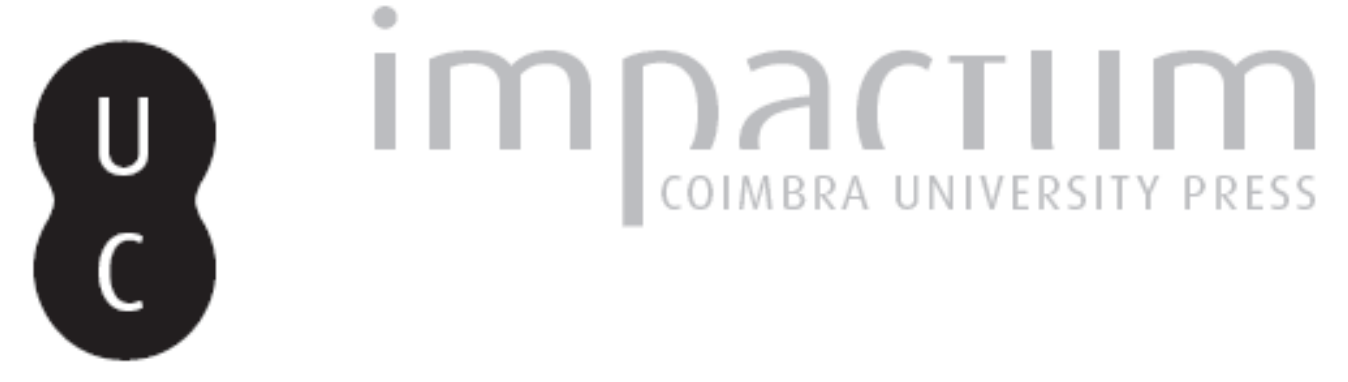

\title{
Bioética e Filosofia: o princípio de autonomia e os desafios da fragilidade
}

Autor(es): $\quad$ Portocarrero, Maria Luísa

Publicado por: Faculdade de Letras da Universidade de Coimbra, Instituto de Estudos

URL

persistente: URI:http://hdl.handle.net/10316.2/34105

DOI: DOI:http://dx.doi.org/10.14195/0872-0851_44_7

Accessed : $\quad$ 26-Apr-2023 15:06:26

A navegação consulta e descarregamento dos títulos inseridos nas Bibliotecas Digitais UC Digitalis, UC Pombalina e UC Impactum, pressupõem a aceitação plena e sem reservas dos Termos e Condições de Uso destas Bibliotecas Digitais, disponíveis em https://digitalis.uc.pt/pt-pt/termos.

Conforme exposto nos referidos Termos e Condições de Uso, o descarregamento de títulos de acesso restrito requer uma licença válida de autorização devendo o utilizador aceder ao(s) documento(s) a partir de um endereço de IP da instituição detentora da supramencionada licença.

Ao utilizador é apenas permitido o descarregamento para uso pessoal, pelo que o emprego do(s) título(s) descarregado(s) para outro fim, designadamente comercial, carece de autorização do respetivo autor ou editor da obra.

Na medida em que todas as obras da UC Digitalis se encontram protegidas pelo Código do Direito de Autor e Direitos Conexos e demais legislação aplicável, toda a cópia, parcial ou total, deste documento, nos casos em que é legalmente admitida, deverá conter ou fazer-se acompanhar por este aviso. 




vol. 22 - número 44 - outubro 2013

vol. 22 - número 44 - outubro 2013 Fundação Eng. António de Almeida

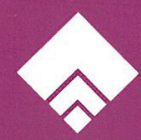




\title{
BIOÉTICA E FILOSOFIA: O PRINCÍPIO DE AUTONOMIA E OS DESAFIOS DA FRAGILIDADE
}

\author{
MARIA LUÍSA PORTOCARRERO*
}

Resumo: Este artigo procura meditar a fecundidade da relação entre Bioética e Filosofia (Hermenêutica) a partir da questão hoje tão importante da «reconfiguração da autonomia a partir de uma ética narrativa da vulnerabilidade».

Abstract: This article aims to meditate the fecundity of the relationship between Bioethics and (Hermeneutics) Philosophy from the today`s so important question «autonomy`s reconfiguration from an narrative ethics of vulnerability».

Palavras chave: autonomia, identidade, ipseidade, consentimento, vulnerabilidade, deliberação, narrativa.

Key words: Autonomy, identity, selfhood, consent, vulnerability, deliberation, narrative.

I - Na introdução do sujeito na medicina viu F. von Weizsäcker, célebre médico alemão, com quem o filósofo H.G-Gadamer muito dialogou ${ }^{1}$, a grande característica da medicina do séc. XX. Este importante acontecimento, diz-nos também P. Laín Entralgo, médico e filósofo espanhol, surgiu na segunda metade séc. XIX, como uma resposta não deliberada ao fenómeno histórico social de rebelião do sujeito na medicina ${ }^{2}$. Aconteceu com efeito, nesta época, a revolta clínica e social do indivíduo doente e do indivíduo

\footnotetext{
* Departamento de Filosofia, Comunicação e Informação (FLUC).

1 Cfr. H.G-GADAMER, O mistério da saúde. O cuidado da saúde e a arte da medicina, trad., Lisboa, ed.,70, 1997.

2 P. L. ENTRALGO, Antropología médica. Para clinicos, Barcelona, Salvat, 1984, pp. 448-449.
} 
são - este enquanto doente potencial -, contra a medicina tradicional, porque ela diferenciava escandalosamente pobres e ricos e tinha o seu fundamento teórico na ciência puramente mecanicista da natureza. Uma medicina que objetivava o doente, tratando-o como caso anónimo e mero objeto de investigação estatística, um corpo objeto e não um corpo vivido, a medicina do séc. XIX ${ }^{3}$.

Foi o movimento operário da segunda metade do séc. XIX, diz-nos ainda Laín Entralgo, o grande impulsionador desta transformação que teve como um dos seus principais objetivos a reforma da assistência médica ao proletariado. Reforma que deu origem a uma melhoria das condições humanas e das técnicas de tratamento e consideração do doente que deixa de estar à mercê da bondade e da simpatia do médico. Assim surge a socialização da assistência médica, evento extraordinário que, pelas suas consequências antropológicas e éticas, introduziu uma primeira personalização do doente nos cuidados de saúde. Perguntemos então: como é que todo este processo conduz ao princípio de autonomia? É isto que tentaremos ver na primeira parte, para depois na segunda repensarmos a autonomia a partir da fragilidade.

Digamos, em primeiro lugar, que foi extraordinária a mudança de atitude do doente relativamente aos cuidados de saúde: se desde a Idade Média até ao séc. XX, o enfermo considerava a ajuda técnica à sua doença com um ato de pura benevolência, no decurso do séc. XX, passou a considerá-lo como um direito inalienável. Além disso, enquanto até ao séc. XX., a doença era para qualquer pessoa uma tragédia ou calamidade, há já muitos anos que, sem deixar de ser um infortúnio pesado ou leve, ela é fonte de um direito social até de ordem económica, uma vez que o doente tem direito a um apoio económico 4 .

Também a atitude médica mudou radicalmente a sua orientação: em primeiro lugar, o médico adquire a condição de funcionário público e a correspondente atitude ética, a moral que lhe é exigida. Em segundo lugar, começou a ser submetido à condição de todos os médicos de hoje, sejam eles funcionários ou não: o de especialista que age de forma científica propondo cuidados e cura, um técnico ou prestador de técnicas e biotecnologias que, por sua vez, vão adquirindo uma grande sofisticação e uma certa autonomia.

Mas se a especialização médica foi uma conquista inalienável, não esqueçamos que ela foi levantando simultaneamente problemas inéditos, nomeadamente de ordem ética. Para melhor os avaliarmos relembremos o contexto da segunda metade do séc. XX, imediatamente a seguir à II grande guerra, época em que o homem foi pela primeira vez confrontado, de modo brutal, com o trágico do sofrimento e o carácter inexplicável do mal, através

\footnotetext{
3 IDEM, ibidem.

4 IDEM, ibidem, p. 451.
} 
do choque causado pela manifestação de possibilidades técnicas de manipulação e destruição da própria humanidade. Capaz do maravilhoso, o homem toma aqui pela primeira vez consciência de uma outra possibilidade: o seu poder-fazer terrível.

A experiência da guerra deixou, de facto, uma séria advertência sobre os riscos e perigos que o desenvolvimento da ciência pode conter no seu seio. Irrompe então o problema da insustentabilidade do pressuposto de neutralidade da ciência tal como a ideia de que a separação entre conhecimento puro e aplicado é claramente oportunista. Surge o problema da responsabilidade do investigador e esboçam-se as primeiras questões sobre a necessidade de um novo ethos para a ciência. Ao nível da saúde, os estados europeus, reagindo ao trauma da guerra e suas atrocidades e interessados numa verdadeira reconstrução e promoção do bem-estar, criaram um organismo no seio da ONU, a OMS, que passou a ter como tarefa velar pela saúde e o bem- estar dos cidadãos. Em 1946, esta mesma organização vai definir, de uma forma nova e revolucionária, a saúde. Ela já não é concebida como a ausência de enfermidades mas como um estado de completo bem estar fisico, social e mental.

No entanto, vários serão os problemas suscitados por esta conceção tão visionária quanto envolvente ${ }^{5}$. Consideremo-los apenas ao nível da relação médico doente: em primeiro lugar, a saúde, identificada com o bem-estar social alarga extraordinariamente o seu perímetro; invade todos os âmbitos da vida humana transformando a medicina num novo poder especializado, capaz de ditar o que é normal e justo, o que deve ou não ser. A medicalização da vida quotidiana instala-se no Ocidente e com ela um novo imperativo social: ser saudável. Exigência que implica uma responsabilização do cidadão e cuja enunciação acaba mesmo por determinar, simultaneamente, os contornos do desvio, da marginalidade e da possibilidade do mal. Expliquemo-nos melhor: uma vez que a saúde é, desde o séc. XIX, um direito universal do homem e a moral da segunda metade do século XX, é a moral do bem-estar social, a apologia do saudável instala-se, os estigmas sociais renovam-se e os estados europeus promotores e protetores do bem-estar vão ter necessidade de multiplicar as políticas de consciencialização, responsabilização e realização da saúde pública, de promoção da saúde e prevenção da doença.

É este o contexto em que os Estados Providência do séc. XX desenvolvem, os sistemas nacionais de saúde, procurando responder às necessidades da saúde pública. É também este o verdadeiro pano de fundo que vai determinar a consideração do doente como pessoa autónoma e portadora de direitos, tendo uma dignidade e capacidade crítica face ao progresso das biotecnologias e ao seu uso no âmbito da saúde.

5 VICTORIA CAMPS, Una vida de calidad. Reflexiones sobre bioética, Barcelona, Ares y Mares, 2001, pp.97-98. 
Antes dos anos cinquenta do séc. XX, diz-nos E. Cassel ${ }^{6}$, neste contexto, num texto sobre a pessoa como sujeito da medicina, esta «não fazia parte da medicina». O respeito pelos pacientes fazia parte dela e a benevolência era 0 princípio ético fundamental. A máxima - «trata o doente como uma pessoa» - impôs-se, de facto, a partir da segunda metade do séc. XX. Isto aconteceu não apenas porque sob os médicos pesava, desde Auschwitz, a recordação da ignomínia praticada por colegas que, no intuito de fazer progredir a sua ciência, usaram pessoas como material gratuito. Mas, porque os próprios avanços da medicina tornada, entretanto, altamente dependente da eficácia da tecnociência e alargando de forma inimaginável o âmbito dos seus poderes, começaram a levantar problemas éticos importantes, que traduzem afinal uma consciência clara de que não se deve nem pode manipular o doente, um ser vulnerável, seja qual for a sua raça ou condição social. São as experiências de manipulação que fazem ressaltar o valor da dignidade humana que assim se afirma por meio de experiências de contraste. Neste sentido, a Bioética impõe-se com toda a sua força, a partir dos anos setenta do séc. passado, como uma rejeição da manipulação e como uma ética prática que levanta uma série de desafios ao pensamento moral e político dos filósofos. Ela coloca, com efeito, subliminarmente um problema ético e político fundamental, que podemos resumir deste modo: o que vamos, nós sociedades contemporâneas, fazer com todas as possibilidades de manipulação e intervenção no desenrolar da natureza, de que dispomos. Podemos? Devemos? Não comprometeremos a dignidade humana? $\mathrm{O}$ que acontece à nossa autonomia $\mathrm{e}$ como realizá-la, quando existem hoje variadas possibilidades de transformar o homem, ao sabor das modas ou mesmo de eventuais ditadores que venham a impor uma norma acerca do que é ou não saudável e até humano?

Etica, autonomia, proteção dos vulneráveis, responsabilidade e justiça são assim as grandes questões levantadas pela nova praxis altamente técnica do médico que sempre lidou com o sofrimento e que, por isso, sempre soube que o indivíduo passa à frente de todo o coletivo, que o fraco interpela muito mais do que o forte, o homem mais do que os deuses, que o lugar mais profundo da alma é também o mais profundo do corpo e que toda a ajuda ou serviço prestado é sempre singular e incondicional.

Com efeito, enquanto anteriormente a técnica não anulava a figura do cuidar própria do médico de família e os médicos não hesitavam em impor o seu juízo aos doentes, hoje ao contrário, com as equipas, surge o anonimato e porque da tecnociência depende a própria qualidade da medicina, a necessidade de informar os pacientes e de os tornar colaboradores nos cuidados de saúde tornou-se a nova regra. A passagem de uma situação à outra reflete

${ }^{6}$ CASSEL, E., «La persona como sujeto de la medicina», in Cuadernos de la Fundació Grífols i Lucas, Barcelona, nº 19. 
a mudança social introduzida pelo poder profilático do Estado social e as transformações do agir e das mentalidades proporcionadas pelo desenvolvimento das biotecnologias. Assim, enquanto outrora se dava valor ao princípio da beneficência, hoje respeita-se a autonomia e o direito dos indivíduos a escolher o seu próprio bem e a tomar as decisões que melhor lhes convêm. Surge neste contexto, o princípio da autonomia em bioética com o seu corolário essencial, o princípio do consentimento informado.

Em termos filosóficos, podemos dizer que a autonomia de que nos falava Kant, o respeito fundamental pela pessoa como fim em si, logo como ente que não se pode vender, destruir, manipular é apropriada pela Bioética que claramente surge como expressão de uma forma de consciência solidária, que recusa a manipulação da pessoa ou doente. Além disso, o médico recusa identificar-se, na sua relação com o doente, com a pura tecnologia médica, de que dispõe, manifestando deste modo a sua própria autonomia face a uma prática clínica cada vez mais automatizada e mediada por aparelhos altamente sofisticados. Sabe que antigas fatalidades, atribuídas à natureza ou mesmo ao destino, caem hoje sob a alçada da sua responsabilidade e que a própria tecnologia, de que dispõe, possui uma autonomia própria que simultaneamente o assusta e fascina. Sabe, em suma, que deve levar a sério a autonomia do doente e obter o seu consentimento informado.

Assim se transformou o respeito pela autonomia e o seu corolário fundamental, o princípio do consentimento informado, no novo lema da ética médica.

II - «Consinto, logo existo», digamo-lo com Michela Marzano. Este passou a ser o princípio moderno de distinção entre atos lícitos e ilícitos ${ }^{7}$, cujos excessos a referida filósofa critica, questionando a sua ligação com o princípio da autonomia. Com efeito, este princípio de raiz kantiana, tendo sido assumido pela Bioética, como medida de proteção dos vulneráveis e expressão de respeito pela dignidade, acaba hoje transformado, muitas vezes, num simples pró-forma ou numa expressão pura e simples vontade subjetiva.

E devemos perguntar: porque é que isto acontece? E indo ainda mais longe: em nome de quê é que um ato desejado e escolhido pode ser classificado de moral? Não haverá atos escolhidos que são claramente imorais? Será o consentimento, sempre, uma expressão da autonomia individual? Não será por vezes ilusório? Como esquecer que, em muitas ocasiões, o indivíduo dá o seu consentimento, sem estar realmente informado? Qual o tipo de laços que poderão existir entre os conceitos de autonomia, de liberdade e de dignidade da pessoa? Estará o doente realmente em estado de tomar uma decisão rela-

7 M. MARZANO, Je consens donc je suis,.... Éthique et autonomie, Paris, Puf, 2006, p 1 . 
tiva à sua saúde, quando se encontra em situação de franca vulnerabilidade? ${ }^{8}$ Não poderão os médicos desviar o consentimento dos seus objetivos iniciais e transformá-lo em proveito próprio? Como, de facto, «resistir à tentação do lucro ou do proveito pessoal, evitando usar o seu poder de persuasão para com um ser fácil de manipular, quando não se é virtuoso» ${ }^{9}$, em sentido aristotélico?

Além de que se de facto é verdade que cada pessoa tem o direito de deliberar, a partir dos fins que visa e dos valores que quer promover, também é verdade e sabemo-lo hoje, que ninguém se resume à sua racionalidade, que o inconsciente tem um grande papel muito importante no processo de decisão e que cada um de nós «vive sempre espartilhado entre o desejo de realização e a necessidade de autodestruição» ${ }^{10}$. Era já esta a condição humana, celebrada pela tragédia grega, na sua real fragilidade.

E não será mesmo hoje frustrante saber que por exemplo, no caso de um doente internado com uma doença renal, o médico conhece todos os problemas e pormenores deste órgão, chegando até ao nível molecular, mas não saiba nada - porque nunca o estudou - sobre a deterioração mental deste doente e sobre o modo como ela se exprime? ${ }^{11}$ Porque será que muitas vezes se esquece que a experiência da doença, vivida como uma alteração da identidade, é acompanhada por efeitos físicos, psicológicos e cognitivos que podem por em perigo a sua capacidade de deliberar e de compreender os tratamentos propostos com um mínimo de objetividade. Como refere Canguilhem, a saúde expressa-se na capacidade de ser normativo, ou seja, de instaurar normas adaptadas às variações das condições do ambiente. Ora, a doença é uma redução desta capacidade. Assim, se a doença não é aos olhos do doente uma perda da normalidade, ela é, no entanto, a redução da sua capacidade para instaurar novas normas ${ }^{12}$.

É preciso mesmo perceber, como nos diz a este respeito E. Cassel, que com a autonomia e o consentimento, acabamos muitas vezes por esquecer que a doença é o maior ladrão da autonomia ${ }^{13}$. Com efeito, também podemos definir a doença de um ponto de vista fenomenológico como um esforço impotente para ser si mesmo; a liberdade que se afirma no esforço é uma

8 IDEM, ibidem, p.7

9 CORINNE PELLUCHON, L'autonomie brisée. Bioéthique et philosophie, Paris, Puf, 2009, p.44.

10 M. MARZANO, op.cit., p. 12.

11 ERIC CASSEL, «La persona como sujeto de la medicina», in Cuadernos de la Fundació Grifols i Lucas, Barcelona, Fundació Grifols i Lucas, n ${ }^{\circ}$ 19.,p. 53.

12 L. BENAROYO, C. LEFÈVE, J.C. MINO, F. WORMS, La philosophie du soin. Éthique, médecine et société, Paris, Puf, 2010, p. 25.

13 ERIC CASSEL, op.cit., p.50. 
liberdade finita que encontra na doença uma resistência que a limita interiormente. A vivência da doença liga assim a liberdade à vulnerabilidade e ameaça seriamente o nosso poder de existir e de compreender. Por outro lado, este esforço impotente do doente para ser si mesmo é simultaneamente a esperança de poder ser por meio da ajuda do outro.

Neste contexto, revela Cassel a sua surpresa para com um mundo, como o de hoje, em que se animam os pacientes a tomar as suas próprias decisões e a eleger o que querem, no exercício da sua autonomia, e em que o médico se limita a maioria das vezes a ser um mero provedor de informação ${ }^{14}$.Poderemos contentar-nos com uma versão da meramente legalista da autonomia e esquecer que as caraterísticas da doença severa impedem que as pessoas pensem e atuem de um modo autónomo? Não nos descreveu já von Weizsäcker as categorias patogénicas através das quais o paciente percebe a sua doença e sofrimento por meio de traços tais como: perda de controlo de si, isolamento, dependência relativamente aos outros, medo da morte, alteração da consciência íntima de tempo. Não implicará o sofrimento uma crise de sentido na medida em que tudo aquilo em que o doente investiu fica ameaçado? ${ }^{15}$

Eis as grandes questões que, no contexto da problemática da autonomia e do consentimento informado, a Bioética coloca hoje à filosofia, provocando-a pensar mais e a esclarecer a origem e o sentido do conceito de autonomia, em ordem a poder finalmente reconfigurá-lo à luz da fragilidade e da doença. A Bioética pode hoje ser para o filósofo o verdadeiro laboratório onde ele esclarece e ajusta os seus conceitos, uma vez que muitas das questões suscitadas hoje pela Medicina dizem respeito à filosofia, à moral e à política. Não esqueçamos, por exemplo, que a doença nunca é um facto totalmente objetivo: é sempre avaliada em função dos nossos valores, das nossas representações sociais e potencialidades económicas e não apenas das nossas sociedades. Veja-se, nomeadamente, as questões relativas à eutanásia e ao estatuto do embrião.

III - Cumpre-nos, então, refletir antes de mais sobre o sentido originário dos conceitos de consentimento e de autonomia. Consentir significa originariamente, diz Marzano, aceitar que uma coisa se faça e não a impedir; significa ainda aprovar, subscrever autorizar, permitir. A palavra oscila assim entre um sentido negativo - não impedir - e um positivo, aprovar ${ }^{16}$. O sentido positivo implica uma participação ativa da vontade ou do desejo e o negativo uma outra forma de tomar parte. Consentir é uma forma de atestação de capacidades, um meio que tem a pessoa de manifestar a sua opinião e as

\footnotetext{
14 IDEM, ibidem, p. 48.

15 L. BENAROYO, C. LEFÈVE, J.C. MINO,F. WORMS, op.cit. p. 26.

16 CF. M. MARZANO, op.cit., p.4.
} 
suas preferências, impedindo que outrem decida por si. Por si só, o consentimento não justifica uma conduta moral, logo, a partir do momento em que ele é considerado como expressão da autonomia pessoal, há que saber o que significa concretamente a autonomia.

Autonomia versus manipulação tal tem sido, na sociedade administrada e automatizada em que vivemos, a grande questão de um tempo, marcado pela demarcação do âmbito ético face ao universo religioso e tradicional, enquanto instância orientadora de condutas. A autonomia da pessoa é, na verdade, no Ocidente de hoje, a única fonte de autoridade moral, perante a hybris da tecnociência e após o declínio das grandes narrativas religiosas e dos mitos de integração coletiva ${ }^{17}$.Quer dizer: perdido o referente metafísico e religioso do consenso ético tradicional ${ }^{18}$, é o conceito de autonomia e dignidade da pessoa o único baluarte da recusa ética do critério puramente técnico da eficácia ${ }^{19}$. É no entanto difícil esclarecer o sentido deste conceito. Sabemos que a função expressiva e normativa da noção de pessoa humana nem sequer traduz um real consenso sobre o seu conteúdo ${ }^{20}$. Corresponde, contudo, num tempo em que a urgência da ética é a grande exigência dos próprios homens da ciência -, apesar de se ter tornado, cada vez, mais problemática a justificação última da ética - a um conjunto de convicções sobre os traços fundamentais da condição ou dignidade huma$\mathrm{na}^{21}$. A autonomia quer fundar a ética no direito que tem todo o homem a autodeterminar-se, aparece muitas vezes sem um estatuto preciso e o seu significado tem oscilado continuamente entre duas aceções: a kantiana e a de J.Stuart Mill.

Segundo a primeira ela seria a faculdade que tem o ser humano de se dar a si mesmo a lei da sua ação, isto é, uma máxima que nomeadamente me diz: «Age de tal maneira que a máxima da tua ação seja universal». Segundo a segunda, a de Mill, ela representaria uma expressão de liberdade e de independência. Ora, no Rapport Belmont ${ }^{22}$, ela é definida, de modo muito sucinto nos seguintes termos: «uma pessoa autónoma é capaz de refletir sobre os seus objetivos pessoais e de decidir por si mesma e de agir de acordo com

17 G. HOTTOIS, op.cit., p.119.

18 Cf. H. TRISTAM ENGELHARDT, JR., Fundamentos da Bioética, trad. São Paulo, Loyola, 1998, pp. 28-29. Veja-se também, A. THOMASSET, P. Ricoeur. Une poétique de la morale. Louvain, Presses Universitaires de Louvain, 1996, pp. 3 ss.

19 Cf. "Entretien avec Luc Ferry" in FRÉDÉRIC LENOIR, Le temps de la responsabilité , Paris Fayard, 1991, pp. 215-228.

20 Cf. A. KAHN, "Et l'homme dans tout ça? Plaidoyer pour un humanisme moderne", Paris, Nil, 2000, p.70, ss.

21 Cf. P. RICOEUR, Postface, in FRÉDÉRIC LENOIR, Le temps de la responsabilité, p. 279.

22 Cfr. M. MARZANO, op.cit., p.84. 
esta reflexão». O que quer dizer que negar a uma pessoa o resultado da sua capacidade de reflexão, é faltar ao respeito à sua autonomia.

Vemos aqui que a autonomia não se reduz, de modo algum, à liberdade de seguir as preferências do momento, mas parece querer fundar-se na razão e na reflexão. As escolhas do indivíduo devem revelar a sua capacidade de autodeterminação. É considerada uma pessoa autónoma, aquela que reflete e age de acordo com as suas deliberações e escolhas, e uma pessoa que não é autónoma é, pelo contrário, dependente de outros. Também na obra de Tom Beauchamp e J. Childress, Principles of Biomedical Ethics, de 1978, a autonomia não se resume a ser uma expressão de um desejo súbito e o consentimento exigido exprime, por sua vez, um projeto de autogoverno, isto é, não é apenas a proteção contra a ingerência de terceiros.

Mas pergunta-se: quem é afinal este ser chamado a autodeterminar-se na situação de vulnerabilidade e dependência em que o colocou a doença? Ou ainda com P. Ricoeur: não será a vulnerabilidade aquilo que na condição humana faz com que a autonomia se transforme numa tarefa alcançar na relação com o outro e nunca num dado adquirido por um simples exercício de reflexão?

Se a autonomia dos modernos tem sido o grande paradigma, da própria Bioética, não esqueçamos que ele se afirma, pela primeira vez no Ocidente, como princípio chave de uma antropologia demasiado racionalista. De Descartes a Kant a autonomia do sujeito significa o domínio da realidade social e natural e a afirmação do controlo do espírito humano sobre as coisas. A autonomia começou pois por assinalar a inversão da relação tradicional de domínio da ordem das coisas sobre as estruturas mentais do sujeito. Revelava o domínio progressivo do mundo por uma lógica de conhecer para poder, prever e dominar; implicava o domínio da religião, da educação e da política e da educação pelas categorias do sujeito. Ora, sabemos hoje que este domínio nos escapa e que o próprio Kant nos mostrava já que era necessário refletir, antes de mais sobre as condições de possibilidade de uma tal autonomia ad extra. Assim se iniciava uma nova fase, a da autonomia ad intra, ou seja, uma lógica da liberdade que articulasse todas as figuras possíveis da sua interação com o real.

A autonomia dos modernos acabou por conduzir a um voluntarismo e, com Kant, a idealismo da ação, que a doença e a fragilidade justamente desmentem, de forma crua e dura. Enquanto autonomia moral ou capacidade de se dar a si mesmo uma lei que ultrapasse o conjunto dos condicionalismos que sofremos, para os submeter a um projeto determinado pela razão, ela chamou-se com Kant dever e mostra-se hoje insuficiente nas situações de conflito ético colocadas à bioética. Ela permite, de facto, proteger os direitos dos doentes, é uma ética do dever; sacrifica, no entanto, os interesses par- 
ticulares, dado que o seu objetivo inicial é tornar possível a autonomia de todos e assim uma harmonia comparável à harmonia natural. A autonomia era expressa aqui na linguagem da obrigação e da norma constringente que se aplica sem exceção. Ora, ela é hoje denunciada no seu estatuto de pilar da filosofia moral porque pressupõe uma imagem demasiado rígida do agente moral e porque obriga o juízo e a ação moral a uma imparcialidade que não toma em linha de conta as contingências e as singularidades das nossas relações concretas com os outros. Por outras palavras, ela esquece o trágico da ação, a necessidade da deliberação circunstanciada e do conselho.

Digamos pois que o conceito filosófico de autonomia surge pela primeira vez na ordem filosófica, no contexto de uma antropologia individualista, a da Aufklärung, com o intuito de realizar o projeto de emancipação plena do homem; que ela supunha uma vontade de afirmação total do homem sem outra mediação que não fosse a da liberdade, isto é, a da sua ação individual sobre o todo.

Ora, hoje não acreditamos mais nesta forma ilusória de autonomia. A autonomia define-se filosoficamente, nos nossos dias, pela sua localização no campo do saber ou da ação e pela sua diferenciação relativamente à totalidade histórica e social. Ela é, do ponto de vista ético e político, uma maneira de o homem se inscrever no todo e de se implicar eficazmente num estado do mundo. Modificada nas suas pretensões pela crítica da razão histórica, ela perdeu os seus excessos e sabe que na sua raiz está uma matriz de afirmação originária ou estima de si que é dialógica e se realiza apenas com o outro; ela exprime uma singularidade que se opõe a desejos totalitários, à possibilidade de alienação ou manipulação. Mas não à fragilidade porque esta é também a sua condição. Autonomia e vulnerabilidade, lembra-nos P. Ricoeur, predicam-se do mesmo homem que é em si mesmo uma coisa e outra, isto é uma desproporção, sob pontos de vista diferentes. Além de que os dois termos se completam: «a autonomia é a de um ser frágil, vulnerável. E a fragilidade seria apenas uma patologia caso não fosse a fragilidade de um ser chamado a tornar-se autónomo, porque sempre o é de algum modo» ${ }^{23}$.

IV - Como compreender então este paradoxo da autonomia frágil que os filósofos contemporâneos, nomeadamente, de linha hermenêutica sublinham nos nossos dias? Em primeiro lugar, há que perceber a grande mudança que a Daseinsanalitik de M.Heidegger, na sua obra Ser e Tempo, introduziu na consideração do homem e do mundo. O projeto moderno de autonomia - que operava numa lógica de emancipação coletiva, como uma vitória do homem sobre a natureza, por meio de um processo de normalização desta - é agora remetido para uma forma derivada de estar no mundo, porque o Dasein é

23 P. RICOEUR, Le juste , 2, Paris, Esprit, 2001, p.86. 
concebido, antes de mais, como um ser lançado no mundo, logo, temporal, situado e mortal. Com efeito, a grande questão do pensar é agora a do sentido e não a do domínio, pois o Dasein sabe que é mortal, tocado pela angústia e por humores. Ele é também compreensão, explicação e linguagem, mas sabe que bem que a sua possibilidade última é a morte; existe no mundo, de forma temporal, enquanto cuidado e formação de si que implica uma entrega esquecida de si ao sentido das coisas e ao que há a fazer, a obra a realizar, com os outros com os quais faz sentido.

A Hermenêutica da condição humana, finita e sempre relacional descobre pois as ilusões da autonomia moderna, expressas na ideia de independência reflexiva. Sublinha o caráter relacional do estar a ser e a passividade ligada à nossa condição de corpo-próprio e tempo vivido sempre marcado por sucessos e revezes de fortuna e finalmente pela morte. A própria Psicologia e os seus desenvolvimentos sublinham hoje as dificuldades da autonomia, pensada à manira dos modernos, mostrando-nos um homem exposto ao trauma, à alienação e à necessidade de ajuda. É preciso pois, dirá o grande filósofo do nosso tempo, P. Ricoeur, que quer pensar a condição humana, para além do Cogito exaltado da modernidade e do Cogito humilhado de alguma pós-modernidade, partir dos grandes traços da condição finita. O intuito é perceber enfim quem é este ser chamado a ser autónomo; é preciso dilucidar o paradoxo relacional constitutivo do homem capaz, cujos traços positivos têm sempre um reverso, a possibilidade da fragilidade.

Relembremos aqui muito rapidamente a análise ricoeuriana da pessoa como ser capaz de autoestima, capacidade que se exprime pelo poder que todo o homem tem de falar, designando-se a si mesmo perante o outro, pelo poder de agir sobre o curso dos acontecimentos, iniciando uma nova ordem no mundo (o reino do sentido), pelo poder de contar a história da sua vida e de a reunir numa narrativa inteligível e aceitável e pelo poder de se manter a si mesmo como autor dos seu atos e de por eles ser imputável. Este poder ou capacidade, núcleo da nova autonomia, é como nos diz o filósofo, um primeiro passo, uma reivindicação que, no entanto, pode falhar. Logo deve atestar-se e dar testemunho de si, pois em si mesmo é apenas uma potência que se deve tornar ato. Como é que isto então acontece? Por meio de todo um processo de objetivação de si em expressões, testemunhos que o outro lê e reconhece e por meio dos quais aprendemos a perceber-nos como realmente dotados de poder ou da falta dele. É com o outro e não sozinhos que nos tornamos autónomos.

Esta dialética entre poder (capacidade) e afirmação (atestação) é importante e deve ser sublinhada, pois apesar de sermos capacidade/poder, podemos não conseguir afirmar-nos e receber a confirmação da nossa capacidade, isto é, do seu exercício e da aprovação ou sanção do outro. É sempre através 
desta atestação e sanção que me torno autónomo. E é no vocabulário da falta de poder que se expressa a fragilidade que, desde logo, se traduz pela incapacidade da designação de si, da iniciativa, da narração da história da sua vida e da possibilidade de ser responsável.

Mas há também, lembra-nos Ricoeur, ao nível do agir, incapacidades infligidas pela doença, pela velhice e pela violência dos outros homens. Aqui, diz-nos o filósofo, devem considerar-se também as modalidades da distribuição desigual do poder de agir. Muitas pessoas não são simplesmente desprovidas de poder, mas privadas dele, como acontece com a doença. Se o núcleo da autonomia pode ser descrito no vocabulário das capacidades, é a falta de poder ou a sua menorização que exprime a fragilidade. Além de que as figuras da fragilidade agravam-se se tivermos em conta o laço entre afirmação e poder. É que a confiança que tenho no meu poder de agir faz parte desse mesmo poder.

Para além de nos mostrar que é o homem capaz que está na raiz da autonomia e que a cada uma das suas capacidades corresponde exatamente a possibilidade de uma incapacidade, que pode acontecer por meio da doença, de um acidente, da violência ou velhice, Ricoeur mostra-nos ainda que é difícil falar de autonomia sem falar de identidade. Ora, a identidade humana não é um dado, é histórica e temporal e surge de dois modos fundamentais. Dois são de facto os núcleos do que se mantém na pessoa, ao longo do tempo: o carácter que diz respeito à identidade idem, ao que eu herdo com o meu corpo, um genótipo ou o conjunto de traços imutáveis que em qualquer pessoa se mantêm ao longo do tempo. E a ipseidade, que o filósofo define, pelo contrário, pela forma de reflexividade que caracteriza o traço ético mais notável da humanidade: «apesar de o meu desejo poder mudar, apesar de eu poder mudar de inclinação, eu manterei a palavra», ${ }^{24}$ isto significa: eu manter-me-ei. " Existe, de facto, um modelo de permanência no tempo, (diz-nos o filósofo) diferente do caráter. É a identidade conseguida por meio da palavra mantida, a fidelidade à palavra dada. Manter a palavra, diz uma manutenção do si mesmo que não se deixa inscrever, como o caráter, na dimensão do qualquer coisa em geral, mas apenas na do quem" 25 .E apesar de Hume, de Nietzsche e de hoje os moralistas deplorarem nas pessoas a instabilidade dos humores, das paixões, das convicções etc., sabemos que sempre «esperamos do outro que responda pelos seus atos como sendo o mesmo que agiu ontem e que deve prestar contas hoje e sofrer as consequências amanhã $\rangle^{26}$. Quer dizer, ao contrário do caráter, esta identidade, expressa pela promessa, pelo facto de o outro poder contar comigo e que não exige um suporte físico semelhante ao do caráter, é uma outra forma de permanência

24 IDEM, Soi-même comme un autre, p.149.

25 IDEM, ibidem, p. 148

26 IDEM, Le juste, 2, Paris Aubier, 2001, p. 92. 
no tempo, correspondente às práticas vividas, ao modo como o outro permite que o si mesmo atualize as suas capacidades. Logo, é totalmente correlativa da categoria relacional do testemunho e inclui em si a alteridade. Representa o advento da dimensão fiduciária que deve estar na raiz de todo o laço social. São, em suma, as minhas fidelidades relativamente ao outro que me dão uma coesão temporal e uma identidade real.

Tal é, de facto, o significado da ipseidade: poder responder à confiança que o outro deposita em mim, reconhecer-me como alguém com que o outro pode contar, porque ajo de forma idêntica ao longo do tempo e sou, por isso mesmo, capaz ainda de salvaguardar a instituição da linguagem ${ }^{27}$. Isto é, não sou um alienado ou troca-tintas, alguém que compromete a relação intersubjetiva e próprio sentido das palavras. A identidade ipse expressa uma manutenção de si que não tem a ver como o caráter, com o suporte biológico da pessoa mas apenas com o quem que nela se faz. É sobretudo no plano ético da responsabilidade que a ipseidade se deixa entender nos seus contornos: ela expressa a maneira de se comportar da pessoa, de tal modo que o outro possa contar consigo e ainda a ideia de que o si mesmo pode ser obrigado a prestar conta das suas ações perante o outro.

Toda esta lógica de cariz ético e profundamente relacional é por nós apreendida, mostra Ricoeur, por meio da mediação narrativa do mundo e do seu encadeamento infinito de histórias; «A compreensão da vida depende da construção de narrativas» e «a vida é o desempenho ininterrupto de histórias» ${ }^{28}$. Assim o ente que se faz si mesmo volta a si informado do facto de a sua vida ser uma vida com outros e para os outros, em instituições justas, e percebe que não há história de si que não esteja misturada com a dos outros e que não seja avaliada ${ }^{29}$. Entende ainda que a coesão narrativa da sua vida, condição da sua autonomia, já não surge por meio da reflexão, em solilóquio, sobre si ou mediante uma intuição. Porque ela é um processo temporal, surge apenas mediante a narrativa. Nesta linha, uma grande diversidade de autores defende hoje, «que a maioria dos nossos processos psicológicos estão organizados de forma narrativa. A forma como damos sentido ao mundo e a nós próprios faz-se a partir da construção e desconstrução de histórias ${ }^{30}$ É na narrativa, mostra-nos Ricoeur, que a unidade do diverso, que me constitui, pode acontecer.

$\mathrm{O}$ eixo a partir do qual acontece agora o sentido do si próprio autónomo é deslocado então da consciência pura, isolada, para a narrativa de uma vida:

27 IDEM, Soi-même comme un autre,p.149.

28 GERGEN e KAYE (1992) apud M. GONÇALVES, M. R. HENRIQUES, Terapia narrativa da ansiedade. Manual terapêutico para crianças e adolescentes. Coimbra, Quarteto, 2000, p.10

29 Cfr., IDEM, Soi-même comme un autre, p. 194

30 M. GONÇALVES, M. R. HENRIQUES, op. cit., p. 9 
é a narrativa que diz o cuidado do homem permitindo ainda perceber o que é a sua responsabilidade e a possibilidade da sua alienação. Neste sentido, lembra-nos Ricoeur, o valor da literatura: ela é também «um vasto laboratório onde são ensaiadas avaliações, valorações, juízos de aprovação e de condenação, pelo que a narrativa serve de propedêutica à ética» ${ }^{31}$. As variações imaginativas a que ela submete a identidade narrativa da personagem são ainda o grande espaço de exercício das experiências em torno da identidade. A gestão da nossa própria vida como uma história capaz de coerência narrativa (uma discordância concordante) representa, segundo o filósofo, uma competência de elevado nível que deve ser tomada como competência significativa da autonomia do sujeito. Digamos pois que é autónomo um indivíduo capaz de conduzir a sua vida de acordo com a ideia de coerência narrativa.

Ora, não será a doença uma interrupção desta coerência? E uma suspensão da minha inscrição numa ordem simbólica comum, aquela que funda a singularidade e a autonomia? Não será então necessário ver na autonomia do doente um ponto de chegada e não apenas um ponto de partida? Ao colocar em crise uma identidade, por meio de uma limitação das suas capacidades, a vulnerabilidade antropológica submete a autonomia à prova do negativo. Instaura, então, a autonomia mais como um valor e exigência a alcançar do que como existência real. Autonomia e vulnerabilidade são, hoje,de facto, a nova condição da existência.

Digamos pois que as questões da Bioética obrigam a filosofia a precisar os seus conceitos, perturbam a natureza automática da deliberação bem como a ideia perigosa, que se gerou a partir de Kant, a de que a ordem prática é capaz de alcançar uma cientificidade comparável ao saber e à cientificidade requeridos na ordem teórica. Porquê? Na medida em que elas descobrem situações de fragilidade que nos fazem repensar a dignidade. A ética processual, hoje dominante, fundada apenas num princípio de justiça que nada tem a ver com o bem e defendida por exemplo por Engelhardt, como a ética da Bioética, é insuficiente. É uma ética formal que faz do princípio de permissão a chave da decisão e se revela incapaz de responder aos desafios do nosso tempo, dada a sua formalidade e neutralidade aparente. Sabemos aliás que a neutralidade da ética processual, como aliás a de toda a política é apenas aparente. E são justamente os desafios que a bioética impõe ao filosofar (esclarecer conceitos, ir para além do principialismo e da casuística em matéria ética) que obrigam a repensar a ética (nomeadamente a questão da deliberação) e a política e ainda a perguntar pelo homem e pelos limites dos modelos modernos da sua compreensão. Não estaremos hoje numa época nova que nos obriga a repensar valores e a própria questão da humanidade do homem?

31 IDEM, ibidem, p.139. 
Assim não só a Bioética ajuda nos nossos dias a Filosofia a pensar mais como a perceber que os valores são também expressões sedimentadas de avaliações já feitas que traduzem o compromisso entre o desejo de liberdade de consciências singulares e situações caraterizadas eticamente. São como nos lembra Ricoeur «sedimentos de avaliação que servem de suporte às novas avaliações, uma espécie de pontos intermediários objetivos entre processos de avaliação. (....). Mas mesmo apresentada com essa roupagem de quase objetividade a ideia de valor mantém sempre uma ligação com a minha liberdade e com a tua liberdade. Aquilo que tem valor supremo é que eu seja e que tu sejas. A partir daqui há ações que valem mais do que outras. (...). É num valer mais que existe o valor». ${ }^{32}$

Por sua vez a Filosofia, que assim sabe pensar, permite conceber a racionalidade da Bioética e dar aos estudantes de medicina e aos profissionais de saúde, que o desejem, uma formação de qualidade que os ajude a formular os seus próprios pontos de vista, a alargar os seus horizontes culturais, a adquirir o sentido do problema e a comunicar com os doentes provenientes de um meio cultural diferente dos seus.

Voltando à nossa questão central: e se a dignidade do homem tivesse muito mais a ver com a sua vulnerabilidade e com abertura ao outro do que com a razão e a capacidade de se autodeterminar? Pode mesmo acontecer que aprendamos mais sobre o homem entendido como um todo, ao mesmo tempo, biológico, psicológico, social moral e espiritual, nas experiências em que a sua dignidade está comprometida do que na relação entre liberdades normais ou rivais.

Perguntemos então: poderá o profissional de saúde estar realmente atento a esta questão? Que competências exigirá esta aprendizagem da dignidade na fragilidade e para que serve ela afinal? Relembremos aqui as virtualidades da racionalidade hermenêutica que, desde M. Heidegger se impõe no âmbito filosófico, como uma forma de razão próxima da experiência vivida e que desde P. Ricoeur trabalha de forma poética e prática a fragilidade humana ou o homem misto, porque lábil e capaz. A filosofia hermenêutica, nem dedutiva nem indutiva, mas interpretativa, isto é, nunca dispensando uma consideração do caso particular, logo uma aplicação que respeite a situação singular, visa orientar as ações dos seres humanos aí onde as exigências de deliberação se fazem sentir com urgência. Contrapõe ao intelectualismo moral da tradição ética um saber prático do justo meio, resultante das experiências conflituais básicas da existência, mediante uma reinterpretação da conceção aristotélica da praxis, da phronesis e do ethos ${ }^{33}$.

32 P. RICOEUR, «O problema do fundamento da moral» in Études Ricouriennes/ Ricoeur Studies, vol $2 N^{o}$ 2(2011), p.136. http:// Ricoeur.pitt.edu

33 Cfr. neste sentido, H.G-GADAMER, Le problème de la conscience historique, Paris, Louvain, Nauwelaerts, 1963. p.49 ss. 
O conhecimento ético, foi com efeito muito claramente diferenciado por Aristóteles do saber puramente teórico ou técnico, porque nos remete para uma forma de verdade (o bem) que nada tem de abstrato ou de taxativo. Existe pelo contrário nos seus múltiplos modos de acontecer, sempre em situações concretas, à partida imprevisíveis e coloca, por isso, uma tarefa de reconhecimento, de deliberação e de integração interpretativa a toda a lei moral. Esta não é de todo semelhante às leis universais da natureza, dado que precisa de ser interpretada/aplicada mediante uma razão experiencial. A phronesis de Aristóteles trata justamente, como a razão hermenêutica, do que pode ser de outro modo, logo do que precisa de deliberação. E segundo ainda Aristóteles é necessário que aquele que se propõe aprender sobre as coisas boas e justas tenha sido conduzido pelos seus costumes. A forma de responder na filosofia prática, lembra-nos o Estagirita, é atender aos tópicos ou seja às opiniões que são admitidas por todo o mundo, pela maioria das pessoas ou pelos filósofos. Não há uma razão prática universal que esteja acima do êthos concreto. A phronesis, cujo modelo de racionalidade a hermenêutica hoje adota, exerce-se sempre dentro de um êthos concreto, que é sempre possível de rever e de corrigir. Enquanto inteligência ética é experiencial, está ligada ao phrónimos, o sábio prudente que exerce o seu saber em cada experiência. No entanto, este exercício não é um mero fazer, é também um padecer, um sentir-se impelido. Com efeito, o êthos diz respeito à totalidade do nosso agir, do nosso pensar e falar no contexto dos costumes que nos sustentam. É a experiência vivida que serve de fundamento à própria razão prática e que sustém o conteúdo do nosso pensar e sentir. Desta experiência parte toda a hermenêutica que exige tal como a Bioética a participação dos afetados e assim recusa o modelo da objetividade causal da ciência. Recorre, por isso, ao modelo textual e narrativo de encadeamento das coisas humanas (mythos), de acordo com a lógica do verosímil que sabe passar da multiplicidade das peripécias ao universal poético da condição humana. É o enredo ou trama que aqui estabelece uma síntese dos elementos discordantes e é assim que graças ao mythos ou enredo, a narrativa agrupa acontecimentos heterogéneos e consegue efetuar uma história completa, com princípio meio e fim e capaz de ser seguida. A narrativa habitua-nos à autonomia relacional, ajuda-nos a organizar a experiência e representa o mundo da ação recorrendo à imaginação.

V - Deste modo, nos dias de hoje, tanto a literatura como o cinema podem ser utilizados como espaço de aprendizagem desta autonomia relacional e da racionalidade prática, dado que a intriga é o grande laboratório onde ensaiamos a nossa capacidade de juízo moral. A narrativa é, de facto, já desde a Poética de Aristóteles, um processo de inteligibilidade importante 
para compreender a praxis, que nos conduz a uma sabedoria prática. Esta distingue-se da teorética na medida em que nos permite perceber o real em ato, sendo assim um método de descrever de novo, no qual a função reveladora procede da estrutura lógica da narrativa e a nova descrição tem como referente a própria ação ${ }^{34}$. Na poética, a imaginação trabalhada à escala do texto, como produção, permite compreender o próprio processo de motivação e distinguir o modelo da causalidade física da lógica da intencionalidade e da motivação. O mythos poético é um modelo de ordenação e de iniciativa com um princípio, um meio e um fim, que permite esquematizar os projetos humanos, figurar os seus desejos, ensaiar o seu poder de fazer, compreender as suas razões de agir e ainda entender a codificação social que enquadra toda a ação individual.

Então para a deliberação em Bioética a mediação narrativa constitui a oportunidade de ensaiar uma racionalidade prática de tipo deliberativo. $\mathrm{O}$ enredo narrativo dá a cada um de nós a oportunidade de nos colocarmos no lugar dos outros, de aprendermos conflitos de valores, tempos vividos de forma dramática ou exemplar e ajuda-nos a organizar a nossa própria experiência, de uma maneira que a torna compreensível de acordo com a lógica dos motivos e da intencionalidade. É então tarefa da sabedoria prática cultivar em quem a pratica a imaginação criadora, por meio de um recurso à racionalidade poética e narrativa, em ordem a recuperar a flexibilidade necessária à ponderação aristotélica. Não há de facto ação sem imaginação: esta interfere desde logo ao nível do nosso projeto, da nossa motivação e ao nível do nosso próprio poder de fazer. A própria coisa a fazer implica da nossa parte uma certa esquematização da rede de fins e meios, isto é, o esquema do pragma. «É neste ponto que o jogo pragmático se cruza com o jogo narrativo (...): a função do projeto voltado para o futuro e a função da narrativa virada papara o passado trocam então os seus esquemas e grelhas, indo o projeto buscar à narrativa o seu poder estruturador e recebendo a narrativa do projeto a sua capacidade de antecipação» ${ }^{35}$. Além de que é no âmbito do imaginário aberto pela ficção que eu ensaio o meu poder fazer e tomo o pulso ao que posso.

Deste modo e porque a narrativa é a grande ocasião que temos para propor à nossa imaginação e meditação casos imaginários, fictícios e possíveis que são precisamente experiências de pensamento mediante as quais aprendemos a relacionar aspetos éticos da conduta humana com revezes de fortuna e com a felicidade, aprendemos por meio da sua frequentação a resolver os conflitos suscitados pelo modo de aplicação puramente formal das regras. A imaginação ética, que inclui o conjunto das escolhas difíceis da humani-

34 P. RICOEUR, Du texte à l'action. Essais d'herméneutique, Paris, ed. du Seuil, 1986, p. 223.

35 IDEM, ibidem, p. 224. 
dade e ainda as regras, normas e padrões de ação, alimenta-se da narrativa histórica e da ficção. A Bioética, enquanto tentativa de mediação entre o mundo da ciência biotecnológica e o mundo vivido dos valores procura fundamentalmente encontrar aquilo que é justo, numa situação concreta. Ela é um saber prático que lida com acontecimentos que emergem na contingência do momento e que escapam a uma racionalidade descritiva, cúmplice da neutralidade técnica; logo ela deve recuperar a narração e a deliberação como métodos próprios da ética.

Relembremos ainda que a ética não é a mesma coisa que as regras e normas morais, mas é antes o seu fundamento; é simultaneamente a base da sua permanência e da sua transformação. Sendo visada «de uma vida boa com outros em instituições justas» ${ }^{36}$,e não regra, ela é ao mesmo tempo a intuição de modelos de ação e a imaginação de um desenvolvimento da vida boa. Ora, este curso de vida boa não é concebível sem um «pôr em intriga», que esquematiza acontecimentos da condição humana, estabelecendo uma concordância discordante entre categorias universais verosímeis e aspetos únicos e singulares da existência temporal.

Tal como Aristóteles afirmava da phronesis que esta não se relacionava apenas com os universais mas também e principalmente com os particulares, que são casos concretos do mundo contingente, também podemos dizer que a hermenêutica deliberativa da Bioética é crítica da rigidez do principialismo. Este ilude os possíveis e o que convém em cada caso, limitando deste modo o âmbito da imaginação em ética. Assim reduz a aplicação ética a pura aplicação mecânica de certos deveres e princípios. Procurando desenvolver-se como um meio termo entre o principialismo e o puro casuísmo, a ética hermenêutica ou narrativa, que retoma o modelo aristotélico e hoje se impõe na Bioética, parte do pressuposto que a mediação prudente entre o particular e o universal, ou pelo menos aquela que não anula o específico e particular, exige o desenvolvimento de competências narrativas. Com efeito, diferentemente da explicação causal, a narrativa ordena, pela sua mimese da ação, elementos heterogéneos da experiência prática; tem segundo Ricoeur uma função positiva de revelação e de transformação da vida e dos $\operatorname{costumes}{ }^{37} \mathrm{e}$ nunca é eticamente neutra. Além de que é concebendo a nossa vida, desde o início, por meio da estruturação narrativa que conseguimos organizar a coerência da nossa vida.

São estas as capacidades de compreensão do campo prático que permitem entender o real em ato dos seres humanos e, nomeadamente, a particularidade e intencionalidade dos seus vividos. Para poder tomar uma boa decisão, o cuidador deve pois ser capaz de compreender o paciente; para

36 IDEM, Soi-même comme un autre, p.202

37 IDEM, Temps et récit. III. Le temps raconté, Paris, Seuil, 1985, p.149. 
isso muito contribui não apenas a sua experiência de contacto com seres humanos como o conjunto das narrativas «que o tornaram capaz de passar do episódico à categoria, isto é, de chegar aos problemas universais a partir de histórias concretas de homens e mulheres» ${ }^{38}$. Não há, com efeito, ética sem um mundo marcado por estruturas narrativas; o próprio ato de contar faz parte da experiência quotidiana e o conjunto da nossa literatura histórica e de ficção articula uma humanidade concreta na sua relação ética com o mundo.

Então se a medicina não se reduz apenas a uma série de competências técnicas e se o respeito pela autonomia do doente supõe qualidades morais, a distinção entre factos e valores deve ser percebida e o positivismo em que se apoia a medicina experimental deve mitigado. Saber ouvir o outro e a sua perspetiva, mesmo a mais vulnerável, é algo que se adquire, se desenvolvermos competências narrativas a par das competências construtivistas da ciência. Enquanto formos apenas o homem construtor ou faber da ciência moderna e vivermos regidos pelo princípio económico da eficácia, é toda a dimensão ética da experiência no verdadeiro sentido da palavra e não no laboratorial que nos escapa. A experiência ética é temporal, reporta-se ao bem do particular e da vida concebida como um todo, logo é necessário que tenha o seu fundamento numa espécie de história narrativa, que não seja pura invenção, mas se insira na narrativa «destas comunidades donde retiro a minha identidade ${ }^{39}$. A ética vive fundamentalmente da realização de valores a que a narrativa histórica e a de ficção dão corpo.

Em suma, é preciso cultivar hoje toda uma educação e todo um modo de estar no mundo que nos ensine a ter prazer em atos moralmente bons; estes supõem poder encontrar em cada caso um meio- termo justo entre o excesso e o defeito e são eles que transformam o ser humano num ser virtuoso que visa o meio- termo em todas as decisões. A imaginação narrativa desempenha aqui um papel central na medida em que tem um efeito motor decisivo nas disposições que levam o homem a agir. Pode assim ser chamada, como o faz P. Ricoeur, de « a função universal do possível prático».

38 TOMÁS DOMINGO MORATALLA, Bioética y cine. De la narración a la deliberación, Madrid, Universidad Pontificia de Comillas, 2010, p.47.

39 MacINTYRE, After Virtue. A study in moral theory. Indiana, University of Notre Dame Press, 1981, p. 205 